"Historical Studies on Mortality," special issue, Canadian Studies in Population 39, no. 3-4 (2012): 1-8.

\title{
Crises and trends: Mortality in historical perspective
}

\author{
Alain Gagnon \\ Département de Démographie, Université de Montréal \\ alain.gagnon.4@umontreal.ca
}

\section{Introduction}

It is well known that mortality in the past was dominated by crises. Prior to the industrial revolution, the contours of mortality of most human populations were punctuated with prominent spikes that could not be missed by any observer scanning a parish register for a sufficient number of pages. Choosing a year at random, the series would show more births than deaths and pretty much the same over the next few years or decades. But sooner or later, suddenly, it was there: the dramatic, unpredictable upswing of mortality, pages after pages, carrying off a tenth, a quarter, or even a third of an entire community in a matter of months, if not weeks. Pestilence, famine, and the devastation of war were the main causes of these dramatic episodes, always ready to surge, lurking against the background of what is called, for lack of a better term, "usual" or "normal" mortality conditions. Crises of mortality were not only startling to the first population historians who browsed the historical archives, but were often taken to have dominated the whole of past demographic trends. Studying Scottish population history, Flinn (1977) went on to suggest that in its early stages, the general decline in mortality of the last centuries was largely due to the attenuation of the severity of crisis mortality. French historical demographer Jacques Dupâquier (1976) devised a measure of "crise de mortalité" that became standard in the historical demography of mortality.

Owing to these crises, large numbers of our predecessors died very early in life and their expected lifespan did not surpass 30 to 40 years in most instances. Between 1800 and 2000, however, life expectancy at birth rose to a global average of sixty-seven years (Riley 2001) and to more than 75 years in developed countries like Canada (Bourbeau and Smuga 2003). At the end of what came to be known as the epidemiological transition (Omran 1971) —a gradual shift from epidemic and infectious diseases to those of a degenerative nature- the most common age at death had jumped from infancy to old age. The articles in this special issue of Canadian Studies in Population tell the story of crises and trends of mortality before, during, and after that transition in Canada and, in one case, in a town of France. We begin with studies on New France and historical France, and progressively move toward studies addressing mortality in a broader and more recent Canadian context.

\section{Prior to the transition}

For a long time, historians were not at ease with the unpredictability of crisis mortality: "Epidemic disease, when it did become decisive in peace or in war, ran counter to the effort to make the past intelligible" (McNeill 1998). Yet, with hindsight — history is always about hindsight, and historical demography is no exception- these events, while they would still be unpredictable in the details of their occurrence, are nevertheless interpretable, and many of their distinctive features are no longer within the realm of the unknown. We now know a great deal about the dynamics involved in historical epidemiological processes, such as the rate of spread of an infectious disease and the factors underlying its incidence or virulence. Thanks to the increasing availability of historical longitudinal micro-data, we also know more about the factors modulating the individual risk during an outbreak, how sex and age patterns of mortality are modified, and how these patterns differ from other times when mortality is simply high, but for other reasons. Who were at the highest risk? Males or females? At what ages? We can now answer these questions with relative confidence. 
What is perhaps less well known, however, are the longer-term consequences for those who were severely infected but survived. Were they at a higher risk during the months or years following an epidemic? Or did they enjoy a lower risk? Sure enough, historical evidence indicates that lifelong immunity was almost invariably acquired for those who had survived infection with a highly virulent agent such as the smallpox virus (Desjardins 1996), although more recent research has demonstrated that infectious disease, when encountered too young, may mark the survivors for life and increase their mortality risk decades after (Bengtsson and Lindström 2003).

But the consequences were not always delayed into old age, and could in some instances materialize in the year following the infection, or a few years after. The paper by Mazan in this issue (2012) is a good example of this. The 1714-15 measles epidemic in New France not only claimed large numbers of young children (Mazan et al. 2009) but had delayed implications for those who survived its acute phase. Using rich family reconstitution data from the "Programme de recherche en démographie historique" (PRDH) at the University of Montréal, Mazan was able to demonstrate that children purportedly infected by the virus before the age of 3 had a higher risk of death until age 5 than their unexposed counterparts, taken from two flanking control cohorts of children, born in 1708 and 1721. The risk was, for instance, up to 2.5 times higher in the case of females exposed at the toddler stage. The risk was also higher for those children who lost a sibling from infection to measles, demonstrating that the intra-familial pattern of transmission of the disease extends beyond its acute epidemic phase. Although these results are based on a historical population, they have an immediate relevance for the epidemiology of measles in contemporary populations. In fact, results from contemporary studies can be affected by the presence of large vaccination campaigns. It has been argued, for instance, that studies conducted in West Africa in the 1990s could have exaggerated the delayed effect of the measles, because these studies were based on a comparison of exposed cases with immunized children. Taking advantage of the fact that immunization was obviously nonexistent in pre-industrial Québec, Mazan thus provides new and useful results, unaltered by modern medicine and public health, which can inform current knowledge about the epidemiology of measles.

Fortunately enough, although causes of death were not systematically recorded in New France's parish registers, Mazan could find historical and circumstantial evidence indicating that the epidemic sweeping through the expanding young colony in 1714 was indeed measles. However, such basic and essential information is not always readily available, and researchers must use other means in order to identify agents responsible for the sudden surges of mortality in the historical record. Devising a new tool combining GIS and demographic data to study epidemics from the past, Seguy et al. (2012) re-examine the evidence regarding an epidemic that struck a French town in Western Provence at the beginning of the 18th century, and call into question earlier diagnoses of dysentery or smallpox. The excess mortality follows a pattern of person-to-person contamination, and does not appear to increase with spatial proximity to a particular place such as a contaminated source of water, as was the case in Snow's (1855) landmark study of cholera in London-whose methodology was recently replicated by Fornasin et al. (2011) for an early 19th-century Italian town. Obviously, cholera cannot be among the suspects in the present case, since it did not enter Europe before the 19th century, but other water-borne diseases that caused major crises in 18th-century France have now to be also discarded on the basis of the spatial pattern that has been brought to light. Excess mortality here does not appear be related to an animal vector either, and clusters of death days apart within specific neighbourhoods instead suggest direct contamination between children living in close proximity. Reports from contemporary observers also point to eruptive fevers that have all the traits of those caused by airborne diseases such as measles, whooping cough, or smallpox. The former two would be more likely, mainly because of the well-known patterns of intrafamilial transmission (e.g., increased mortality in secondary cases of older individuals with family ties to the victims at the end of the epidemic). Undoubtedly, further enquiries will be needed to bring the issue to a close, but it is already clear that the approach was helpful in narrowing down the list of possible causes.

Lacroix and Desjardins (2012) also take advantage of the richness of historical data from Quebec in this issue, spanning from the 17th to the mid-19th century. The focus is now on adults, and the study is not about crises but about longer-term trends, as is often the case when the attention shifts from young to older-age mortality. Following individuals for up to 100 years (potentially until 1849 for those born in 1749) with the classical tool of life tables, the study bridges an important knowledge gap on North American mortality for the 18th and 19th centuries. Much of what we know about mortality at the time is based on fragmentary data, since vital statistics are not available for most areas of the continent until the 20th century, and there are no sensitive measures of mortality that can be derived from censuses (Haines 2000). For New France, earlier-cohort life tables were already available from Charbonneau's pioneering work (Charbonneau 1975; Charbonneau et al. 1993), but none extended the follow-up until the middle of the 19th century. 
Introduction by Gagnon (guest editor): Crises and trends-Mortality in historical perspective

Thanks to the development of the Registre de la population du Quebec ancien at the University of Montreal, this is now possible. The study confirms the noted high mortality of women of child-bearing age in the highly fertile population, an excess mortality which might have acted as a selecting factor prompting lower post-reproductive mortality for the survivors (Gagnon et al. 2009). An urban mortality penalty is also reported for dwellers living in Montreal and Quebec City, but not in Trois-Rivières, which was more like a large village than a genuine town at the time (despite its important administrative functions as one of the three chefs-lieu of the colonial government). Yet, as noted in previous enquiries, environmental conditions were in general healthier for the inhabitants of the expanding young colony than for their contemporaries in France. Although winters could be harsh, crops could fail, and food prices could suddenly increase dramatically, the colonists — at least those living in the countryside — had easier access to alternative sources of subsistence from fishing and hunting. Such access was most likely a critical factor during crises that helped to improve survival to old age among the elderly (usually the most susceptible elements of a population) living in the St. Lawrence Valley.

The next four papers of this special issue focus on the more recent past, beginning with the 20th century, and are also concerned with mortality crises and trends.

\section{Halting the transition}

At the time of the 1921 Canadian census, infectious diseases—especially influenza and pneumonia-were still at the top of the list of the principal killers, with 13.8 per cent of all deaths, but their importance had already been largely curbed, with diseases from the circulatory, respiratory, and digestive systems coming immediately after, amounting to 13.5, 12.8, and 10.1 per cent of totals, respectively (Trovato 2009). Similarly, infant and child mortality, which dominated mortality trends up to the end of the 19th century, had already significantly receded by the second decade of the 20th century, even though further considerable improvements had yet to come. Given the remarkable advances in standards of living that accompanied and (according to some) largely fuelled that vast movement from its beginning (McKeown 1976; Fogel 2004), it might have seemed to most contemporaries that nothing could stop the inexorable march of progress.

Yet, the progressive and apparently irreversible transition was to be abruptly interrupted by the biggest killer of all time, the 1918 Spanish flu pandemic. Once again, as in another age, the grim reaper unexpectedly surged, taking away 20-50 million people in a couple of months (Taubenberger et al. 2006) - indeed, many more than what the First World War took in four years. Despite all the progress, despite the better knowledge of what needs to be done in order to fight off the spread of epidemic diseases_-including Pasteur, Koch, the organization of public health, vast sanitization campaigns, and so on-here it was again, a crisis as a dire reminder of a not-so-distant past. But this time, as it seemed, the crisis was a bit different. In "An exploration of the effects of pandemic influenza on infant mortality in Toronto, 1917-1921," Hallman (2012) shows that quite unexpectedly (at least in comparison with past epidemics such as that reported by Mazan and by Séguy et al. in this issue), the infant mortality rate increased only slightly during the Spanish flu crisis. True, in October of 1918, during the peak of the pandemic, infant mortality was 147.8 per thousand in Toronto, which is about 50 per cent higher than the average for the five-year period from 1917 to 1921 (96.91 per thousand). But the increase appears to be largely due to a seasonal pattern. For instance, the rate was of 135.8 per thousand in October 1920 and 137.33 in September 1921. The epidemics of earlier centuries always predominantly affected the youngest elements of society, but not this time, as young adults aged 20-40 were now the main targets. The pandemic did not act on the same epidemiological background as its predecessors from the past, as if it could not fully erase the already left by the ongoing epidemiological transition. After having killed large numbers of people in the prime of their lives, the Spanish flu pandemic was to be quickly forgotten. It left the public consciousness as swiftly as it arrived (Crosby 1989), perhaps because of its incompatibility with the very idea of progress (Herring and Swedlund 2010).

Another main killer also acted as a check to the progression of the epidemiological transition in the first half of the 20th century, albeit in a much more diffuse and less abrupt way. For a few more decades than most other main infectious diseases, tuberculosis continued, year in and year out, to take a heavy toll-particularly among young adults, not unlike what the influenza did in a couple of months in 1918. Tuberculosis is a common and, in many cases, lethal infectious disease, caused by various strains of mycobacteria that typically attack the lungs. Most infections are asymptomatic and latent, but in the past, latent infections often progressed to active disease that eventually killed large numbers of those infected. As such, it was expected in the next contribution by Ludlow and Burke (2012) to increase mortality among the 
miners and industrial steel employees of Glace Bay and Sidney, NS, in the early 20th century. The bacterium is spread through the air when people who have an active infection cough, sneeze, or even just talk loud, and the relative confinement of the miners and industrial workers in restricted and poorly ventilated spaces could have acted as a potent vector of transmission. Worse, with all its well-known associated industrial pollutants and floating particles of all sorts (dust, etc.), such environments represented a significant health hazard on their own, especially for the lungs. It is easy to imagine that combined with tuberculosis, repeated exposure to coal or proximity to an open-hearth coke oven could have increased respiratory disease mortality in a multiplicative way. Yet, nothing of the sort is observed in the case-control study proposed by Ludlow and Burke. Tuberculosis mortality is influenced by a number of predictors, including the worker's age, birthplace, and the community of residence, but not by occupation. Rather, this mortality seems to have been driven mainly by occupational hazards. Relative to non-industrial workers, miners certainly had higher risks of accidental death. Interestingly, however, the differences regarding accidental mortality were not significant when comparing industrial labourers with non-industrial workers. The latter result is not unlike what was found for Saguenay-Lac-SaintJean in the 19th and 20th centuries, where skilled workers who often operated dangerous machinery had notoriously high accident hazards in the workplace, perhaps even more than unskilled workers (Gagnon et al. 2011).

Tuberculosis and influenza were also present and active for quite some time in the 20th century. Even as late as in 1969, the famous American jazz bassist Paul Chambers died of tuberculosis at the young age of 33. As for pandemic influenza, it re-emerged a few times after the dramatic episodes of 1918, particularly in 1957, 1968, and as recently as 2009. But for the most part, infectious diseases, which for a long time halted the progress in life expectancy, had largely receded to very low levels by the mid-20th century. With the completion of the epidemiological transition, the stage was now set for new extraordinary developments that would finally add years of life from above, to older ages, leading to true lifespan expansion.

\section{Living longer together}

The quest for longevity appears to have been a recurrent theme in the history of human societies, but only recently was it possible to improve survival to old age in a consistent manner. Once the sieve of infancy and early childhood mortality was passed, our predecessors were expected to survive half to three-quarters of a century in some cases, but not much more than that. The progress accomplished since then is nothing short of spectacular. The implications are wide-ranging and reverberate in all aspects of life, as far as to redefining what it is to be a human being, living and interacting with peers. "Emotions of life," to quote Riley (2001), have been permanently altered. Whereas a third to a half of our predecessors would not survive to adulthood and participate in the production of the next generation, today virtually all (99 per cent) live to the age of majority. Whereas our ancestors often died in their prime- - be it young mothers succumbing to the latest fever sweeping through the community, or not much older men falling to the latest bad cold—-most of us can now stay in contact with many of our relatives, including most of our siblings, of course, but also our grandparents, grandchildren, great-grandparents, and so on (Uhlenberg 1980).

These remarkable improvements in survival have fuelled the rapid growth of the elderly population. Yet we still know very little about old-age mortality. Cross-sectional analyses of contemporary conditions have shown that the socially and economically disadvantaged generally suffer higher risks of death than their more well-off contemporaries. These analyses, however, often miss the deeper roots of differential mortality, and mounting evidence suggests that conditions experienced in childhood and in the family of origin have far-reaching consequences, mainly because of the persistence of traits acquired early on.

Biodemographic studies going back a century or more have provided much evidence that longevity runs in families, as similarities were found between close relatives" ages at death (Desjardins and Charbonneau 1990). But in these studies it has always been difficult to distinguish what is owed to genes from what is owed to environmental influences—shared as they are, to a large extent, by relatives. The study by Jarry et al. (2012) in this issue innovates by bringing spouses into the picture. While many have studied the longevity correlation between parents and children and between siblings, there has been much less attention paid to the equally important question of similarities between spouses. In comparison with siblings, the early life environment of husbands and wives is much less alike, and it is expected that if spouses benefit from one another's longevity, it is mostly thanks to the environment they shared during adulthood. Based on a sample of 806 centenarians whose siblings and spouses were found in the 1901 and 1911 Censuses of Canada and in the Quebec civil registers, the authors show that indeed, spouses as well as siblings of centenarians live longer than their counterparts 
Introduction by Gagnon (guest editor): Crises and trends-Mortality in historical perspective

taken at random in the population. However, unlike men, women benefited more from having a centenarian among their siblings than from being married to one. Interestingly, the extra survival benefit for husbands of centenarians, suggesting a role for the common environment shared in adulthood, is smaller after age 75, when being a sibling of a centenarian becomes more beneficial. With one foot at the outset of the epidemiological transition and the other in the post-transitional period, the study by Jarry et al. clearly shows why family matters. The study is also another example of how historical demography can inform current knowledge on population health.

Finally, Ouellette et al. (2012) sum up the survival progress accomplished in Canada over the last century or so at the provincial level, and addresses fundamental questions regarding the future of longevity.

It was assumed for a long time that the overall increase in life expectancy would necessarily be associated with reductions in mortality disparities. This was certainly true during the period in which life expectancy increases were essentially due to reductions in infant mortality (Robine 2006). Levelling of mortality inequalities was also expected based on the implicit assumption of a limit to the human lifespan. In this context, further progress could only be fostered by reductions in mortality among less-advantaged groups, communities, or regions. These segments of the population would finally join the more fortunate groups in an overall lower mortality regime that would be translated empirically by the "compression" of mortality and the "rectangularization" of the survival curve in the life table (Fries 1980). But of course, with infant mortality levels as low as 4 to 5 per thousand, it is no longer possible to improve life expectancy from any further reduction of mortality at the youngest ages. Additionally, important gains in survival, now taking place at older and older ages, cast doubt on the notion of a fixed limit to the human lifespan. At the very least they suggest that we are not rapidly approaching this limit, if it exists. What seems to be happening now is that while some sections of society are still engaged in the "mortality compression scenario," other groups are going through a "shifting mortality scenario," such that the bulk of deaths shifts to progressively older ages without changes in the shape of the distribution of mortality. New tools are necessary to describe these movements.

The long-preferred life expectancy measure may have to give way to a modal age at death and standard deviation above the mode. This is by far the best indicator of longevity in a low-mortality population, since it is highly sensitive to reductions of mortality among the oldest old, and not at all as sensitive to variations in infant and child mortality as is life expectancy (Robine 2006). In this issue, Ouellette et al. (2012) develop a sophisticated mathematical approach, and propose the first Canadian study on regional variations in mortality compression, from 1930 to 2007. The P-spline approach introduced earlier (Ouellette and Bourbeau 2011) is generalized, in order to make it applicable to the study of mortality at the provincial level, which involves changes over age and time in relatively small samples. The analysis reveals that despite general improvements in each province over time, disparities in old-age mortality, as measured by the modal age at death, persist to this day. Owing to its strong dependency on young-age mortality, which was equally reduced to very low levels in all provinces, the use of life expectancy alone as an indicator of longevity would have simply missed these disparities taking place at older ages. The study also points to an interesting trend regarding sex differences in mortality patterns at older ages. While in the Western and Central provinces the whole of female mortality distribution appears to be currently shifted to older ages, male mortality from all provinces apparently has not yet ceased its compression movement.

\section{Conclusion}

The seven papers presented in this special issue, six of which are based on Canada, reflect the current research in the historical demography of mortality and the wealth of scientific research in this field. Together, they tell a story of crises and trends, from an era when large numbers of people, often very young, were carried away by the sudden and unpredictable appearance of an epidemic outbreak to an era where the bulk of mortality is relegated to much older ages. The papers are organized in relatively tight chronological order, with some inevitable interruptions as the attention shifts from crises to trends, from young to old, from patterns of infant mortality to patterns involving the whole life course, or as crises are progressively flattened out and progressively turned into trends. The papers offer wide-ranging coverage from both the temporal and geographical points of view, with contributions tracing the mortality experience from the outset of settlement in New France to the latest trends in a broad Canadian context. The themes are varied (infant, adult, cause-specific mortality, longevity), and the methods include the traditional (life table, logistic regression), more recent (event history), and current innovative mathematical tools ( $\mathrm{p}$-splines). The papers all piece together a fascinating story of mortality from the past to today. 


\section{Acknowledgements}

I am grateful to the anonymous reviewers of this special issue of Canadian Studies in Population for their insightful comments and helpful suggestions for revision. The papers in this special issue were initially presented at the 2010 Federation of Canadian Demographers (FCD) meeting at Concordia University, Montreal (June 1-2 2010), and at the last International Conference of the International Union for the Scientific Study of the Population (IUSSP) in Marrakech in September 2009. The theme of the FCD meeting was "Understanding the Populations of the Past: New Developments and Interdisciplinary Perspectives" and five other papers from this conference are published in a special issue of the Cabiers québécois de démographie. The two IUSSP sessions were titled "A historical demography of epidemics" and "Spreading the disease: The demography of diffusion and transmission of contagious agents in the past," and were organized by the Historical Demography Panel of the Union. Finally, I thank Frank Trovato for his useful comments and suggestions on an earlier version of this manuscript.

\section{References}

Bengtsson, T., and M. Lindstrom. 2003. Airborne infectious diseases during infancy and mortality in later life in southern Sweden, 1766-1894. International Journal of Epidemiology 32:286-294.

Bourbeau, R., and M. Smuga. 2003. La baisse de la mortalité: Les bénéfices de la médecine et du développement, in La démographie québécoise, edited by V. Piché and C. Le Bourdais. Montréal: Les Presses de l’Université de Montréal, pp. 24-65.

Charbonneau, H. 1975. Vie et mort de nos ancêtres. Montréal: Les Presses de l’Université de Montréal.

Charbonneau, H., B. Desjardins, A. Guillemette, Y. Landry, J. Legaré, and F. Nault. 1993. The First French Canadians: Pioneers in the St. Lawrence Valley. Newark: University of Delaware Press.

Crosby, H.B. 1989. America's Forgotten Pandemic: The Influenza of 1918. New York: Cambridge University Press.

Desjardins, B. 1996. Demographic aspects of the 1702-1703 smallpox epidemic in the St. Lawrence valley. Canadian Studies in Population 23(1):49-67.

Desjardins, B. and H. Charbonneau. 1990. L’héritabilité de la longévité. Population 45:603-616.

Dupâquier, J. 1979. L’analyse statistique des crises de mortalité, in Les grandes mortalités: étude méthodologique des crises démographiques du passé, edited by H. Charbonneau and A. La Rose. Liège: Ordina Editions, pp. 83-112.

Flinn, M.W. 1974. The stabilisation of mortality in preindustrial Europe. Journal of European Economic History 3:285-318.

Fogel, R.W. 2004. The Escape from Hunger and Premature Death, 1700-2000. New York: Cambridge University Press.

Fornasin, A., M. Breschi, and M. Manfredini. 2011. Houses and individuals in Udine during the cholera outbreak of 1836: A geo-referenced analysis with micro-level data. Genus 67:101-118.

Fries, J.F. 1980. Aging, natural death, and the compression of morbidity. The New England Journal of Medicine 303:130-135.

Gagnon, A., K.R. Smith, M. Tremblay, H. Vézina, P.P. Paré, and B. Desjardins. 2009. Is there a trade-off between fertility and longevity? A comparative study of women from three large historical demographic databases accounting for mortality selection. American Journal of Human Biology 21:533-540.

Gagnon, A., M. Tremblay, H. Vézina, and J. Seabrook. 2011. Once were farmers: Occupation, social mobility, and mortality during industrialization in Saguenay-Lac-Saint-Jean, Quebec 1840-1971. Explorations in Economic History 48: 429-440.

Haines, M.R. 2000. The white population of the United States, 1790-1920, in A Population History of North America, edited by M.R. Haines and R.H. Steckel. New York: Cambridge University Press, pp. 305-369. 
Hallman, S. 2012. An exploration of the effects of pandemic influenza on infant mortality in Toronto, 1917-1921. Canadian Studies in Population 39(3-4):33-46.

Herring, D.A., and A.C. Swedlund. 2010. Plagues and epidemics in anthropological perspective, in Plagues and Epidemics: Infected Spaces Past and Present, edited by D.A. Herring and A.C. Swedlund. Oxford: Berg, pp. 1-20.

Jarry, V., A. Gagnon, and R. Bourbeau. 2012. Survival advantage of siblings and spouses of centenarians in 20thcentury Quebec. Canadian Studies in Population 39(3-4):65-76.

Lacroix, C., and B. Desjardins. 2012. Adult mortality in preindustrial Quebec. Canadian Studies in Population 39(34):21-32.

Ludlow, N., and S.D.A. Burke. 2012. Deadly occupations: Assessing tuberculosis and accidental mortality among male workers in Sydney and Glace Bay, Nova Scotia, 1909-1917. Canadian Studies in Population 39(3-4):47-64.

Mazan, R. 2012. Delayed measles mortality among exposed children who survived the epidemic of 1714-15 in New France. Canadian Studies in Population 39(3-4):7-20.

Mazan, R., A. Gagnon, and B. Desjardins. 2009. The measles epidemic of 1714-1715 in New-France. Canadian Studies in Population 36(3-4):295-319.

McKeown, T. 1976. The Modern Rise of Population. New York: Academic Press.

McNeill, L.H. 1998. Plagues and Peoples. New York: Anchor Books. (First published in 1976.)

Omran, A.R. 1971. The epidemiological transition: A theory of the epidemiology of population change. The Milbank Memorial Fund Quarterly 49:509-538.

Ouellette, N., and R. Bourbeau. 2011. Changes in the age-at-death distribution in four low mortality countries: A nonparametric approach. Demographic Research 25:595-628.

Ouellette, N., R. Bourbeau, and C.G. Camarda. 2012. Regional disparities in Canadian adult and old-age mortality: A comparative study based on smoothed mortality radio surfaces and age-at-death distributions. Canadian Studies in Population 39(3-4):77-102.

Riley, J.C. 2001. Rising Life Expectancy: A Global History. New York: Cambridge University Press.

Robine, J.M. 2006. Research issues on human longevity, in Human Longevity: Individual Life Duration and the Growth of the Oldest Old Population, edited by J.M. Robine, E.M. Crimmins, S. Horiuchi, and Z. Yi. International Studies in Population 4. Dordrecht: Springer.

Snow, J.M.D. 1855. On the Mode of Communication of Cholera. London: John Churchill.

Taubenberger, J., and D. Morens. 2006. The 1918 influenza: Mother of all pandemics. Emerging Infectious Diseases 12:15-22.

Trovato, F. 2009. Canada's Population in a Global Context: An Introduction to Social Demography. Toronto: Oxford University Press.

Uhlenberg, P. 1980. Death and the family. Journal of Family History 5:313-320. 
